\title{
Chapter 24 \\ Early-Life Conditions and Old-Age \\ Mortality in a Comparative Perspective: \\ Nineteenth Century Sweden and Belgium
}

\author{
Tommy Bengtsson and George Alter
}

\subsection{Introduction}

Kermack et al. (1934) proposed the cohort explanation in their analysis of the aggregated mortality decline in England, Wales, Scotland, and Sweden. Their conclusion was that reductions in the death rates of the various age groups attained at any particular time depended primarily on the individuals' date of birth, and only indirectly on the particular year under consideration. The essential effects on health and survival of adults and older persons were mainly caused by improvements and beneficial effects on their respective birth cohorts during childhood several decades earlier. Jones (1956) brought up the cohort approach anew and recently it has gained focus again through works in medicine but also in historical demography (Barker 1994; Elo and Preston 1992; Fogel 1994; Fridlizius 1989; Kuh and Ben-Shlomo 1997; Preston et al. 1998; Finch and Crimmins 2004). The plausible causal relationships between early-life experiences and old-age mortality have been discussed, with special attention to intrauterine cellular development and cellular development during early childhood. Robert Fogel (1994) has proposed several plausible causal mechanisms that connect malnutrition in utero and during early life to chronic diseases in later life. These propositions are also supported by the work of Barker (1994, 1995) who suggested that the preconditions for coronary heart disease, hypertension, stroke, diabetes, and chronic thyroiditis are initiated in utero without

\footnotetext{
T. Bengtsson $(\bowtie)$

Centre for Economic Demography, Lund University, Lund, Sweden

e-mail: tommy.bengtsson@ekh.lu.se

G. Alter

University of Michigan, Ann Arbor, MI, USA

Inter-University Consortium for Political and Social Research (ICPRS), University of Michigan, Ann Arbor, MI, USA

(C) The Author(s) 2019

T. Bengtsson, N. Keilman (eds.), Old and New Perspectives on Mortality

Forecasting, Demographic Research Monographs,

https://doi.org/10.1007/978-3-030-05075-7_24
} 
becoming clinically manifest until much later in life. In contrast, Jones (1956), and later Fridlizius (1989), in his analysis of the aggregated mortality decline in Sweden, proposed that the genesis of disease in later life could be due to exposure to certain infectious diseases in the first years of life. Fridlizius argued that this was caused by life-long reduced immunity, which consequently gave higher general risk of other infectious diseases in later life. The knowledge of the medical mechanisms today seems to be more in favour of permanent retardation of organs due to infections rather than immunological mechanisms (Finch and Crimmins 2004). Either way, it implies that factors other than nutrition are important early-life determinants of mortality in later life, because the outcome of some other important infectious diseases, like smallpox, is almost completely unrelated to the nutritional status of the infected individual (Rotberg and Rabb 1985).

In two recent essays, Bengtsson and Lindström (2000, 2003) investigated the different cohort hypotheses using longitudinal data for individuals instead of aggregated data like Kermack et al., Fridlizius, and many others. Bengtsson and Lindström analysed demographic and economic data for individuals and households and combined with community data on food prices and disease load. The analyses included variables measuring conditions during the fetal stage and the first year of life, as well as the disease load and access to nutrition (food prices). Strong support was found for the hypothesis that the disease load experienced during the birth year had a consistent impact on mortality in later life (Bengtsson and Lindström 2003). This was particularly the case with the outcome of airborne infectious diseases during old age (Bengtsson and Lindström 2000). The hypotheses that access to nutrition and the disease load on mothers during the fetal stage had impacts on mortality in later life were not supported and neither was the hypothesis about the effects of access to nutrition during the first year of life (Table 24.1)

The influence of short-term variations in infant mortality on old-age mortality was due to both cycles in infant mortality and trend (Bengtsson and Lindström 2003). A test of potential nonlinearity of the cycle effect reveals that only years with particularly high disease load had an impact on mortality in later life (Bengtsson and Lindström 2003). Highly virulent infectious diseases, especially smallpox and whooping cough, dominated infant mortality in those years (Bengtsson and Lindström 2003). These diseases are so virulent that the outcome shows no social

Table 24.1 Estimation of effects of infant mortality rate at birth on mortality in ages 55-80 years in various diseases

\begin{tabular}{l|cll}
\hline Death cause & Deaths & Rel. risk & Wald P-value \\
\hline Airborne infectious disease & 343 & 4.65 & 0.00 \\
Non-infectious diseases & 208 & 3.41 & 0.05 \\
Old-age mortality & 339 & 1.46 & 0.45 \\
All causes of death & 1400 & 1.80 & 0.03 \\
\hline
\end{tabular}

Source: Bengtsson and Lindström (2000: table 5)

Note: The model controls for sex, birth year, birthplace, socioeconomic status, time period, and logarithm of current rye prices in four Scanian parishes, 1766-1894. Number of deaths $=1400$ 
gradient, and they probably penetrated the entire population. Smallpox, which was mainly a childhood disease during the eighteenth century, was not only highly virulent but also equally mortal with an overall fatality rate of about $15 \%$ (Sköld 1996: 70-75; Riley 2001). The eighteenth-century pattern of total childhood dominance in smallpox mortality indicates that during this period the majority of the adult population had already been exposed to smallpox as children, and had survived. The fact that airborne infectious diseases in the first year of life particularly affected old-age mortality may imply that exposure to airborne infectious diseases during the first year of life may make individuals more vulnerable throughout life. Cohorts exposed during infancy to such infectious diseases may thus be much more susceptible to high morbidity and mortality rates in old age than cohorts exposed later in childhood to epidemics of smallpox and other infectious diseases. The causal biological mechanisms in early life that might explain these significant associations are only partly known (for further discussion, see Bengtsson and Lindström 2003; Lindström and Davey Smith 2008).

In another recent essay on the effect of different forms of community variables, Bengtsson et al. (2002), analyse early-life links in further detail. The essay supports the earlier conclusion that the functional form of the effect of exposure is nonlinear and includes valuable information about the causal link.

Furthermore, it shows that while both observed and unobserved characteristics at family level - whether the result of genetics or of shared experience - had a significant impact on mortality in later life, their inclusion in the models only marginally alters previous estimates.

The main question in this paper is whether these historical findings for rural Sweden are a local, or possibly a Nordic, phenomena, or if we find the same pattern outside Sweden. We have therefore replicated the study for southern Sweden with one for the rural parish of Sart in eastern Belgium. The population we analyze in Sart are born in the period 1799 to 1846 and followed until 1899. For southern Sweden, we analyze the population born between 1750 and 1840 , followed to 1895 . The longitudinal demographic data on individuals and household socioeconomic data from parish registers were combined with community data on food costs and disease load, using a Cox regression analysis for the mortality among ever-married persons in ages 55-80 years. In addition to trying to answer the main question, we will briefly discuss whether information about conditions early in life can be used to improve mortality forecasting.

\subsection{Models}

We use a proportional hazards model (Cox 1972). This means that we assume that a relative effect on mortality of any covariate is constant over age. The model allows time-varying covariates. It is very important to check the assumptions behind this model, especially the proportionality assumption. We have therefore routinely tested 
all models for deviations from the proportionality assumption. ${ }^{1}$ The test we have used is based on the correlation between $\log (\mathrm{t})$ and the Schoenfeld residuals for each covariate. A large correlation indicates that the corresponding coefficient varies with time, which means that the hazards are not proportional. We found no signs of nonproportionality for any of the covariates or globally. ${ }^{2}$

\subsection{Data for Scania}

The Swedish data come from the Scanian Demographic Database, which consists of records of births, marriages, deaths, and migrations for nine rural.

parishes and one town situated in the southernmost part of Sweden. The material for two of the parishes dates back to 1646 and for the others to the 1680s. The publicly available records end in 1895. Four of the rural parishes - Hög, Kävlinge, Halmstad, and Sireköpinge - are included in this study. The parish register material is of high quality and shows few gaps for births, deaths and marriages. Migration records are less plentiful, but continuous series exist from the latter part of the eighteenth century. Information concerning farm size, property rights, and various other items from the poll tax records and land registers, are linked to the family reconstitutions based on the parish records of marriages, births, and deaths.

Our interest in life-course effects on later-life mortality further limits our dataset. We need information about socioeconomic conditions at birth not only for those born in the parish but also for in-migrants. Data needed to create information for the socioeconomic condition at birth of an in-migrant can be obtained from the birth parish, but is generally available only after 1829 . We have therefore had to limit the period of our analyses to 1829-1894.

The sampled parishes are compact in their geographical location, showing the variations that could occur in peasant society with regard to size, topography, and socioeconomic conditions, and they offer good, early source material. The entire area was open farmland, except northern Halmstad, which was more wooded. Halmstad and Sireköpinge were noble parishes, while freehold and crown land dominated in Kävlinge and Hög. The parishes each had 200-500 inhabitants in the latter half of the eighteenth century. The agricultural sector in Sweden, and Scania, became increasingly commercialised in the beginning of the nineteenth century. New crops and techniques were introduced. Enclosure reforms and other reforms in the agricultural sector influenced the population growth, in particular in Sireköpinge, which experienced rapid population growth. In Kävlinge, the establishment of several factories and railroad transportation led to rapid expansion from the $1870 \mathrm{~s}$ onwards (see Bengtsson 2001 for more details).

\footnotetext{
${ }^{1}$ We used the function 'cox.zph' in the 'survival' package in R.

${ }^{2}$ For a more detailed description of the test, see Therneau and Grambsch (2000: chapter $6,127-152)$.
} 
The social structure of the agricultural sector is often difficult to analyse since differences of wealth between the various categories of farmers and occupations are unclear and subject to change with the passage of time. Land was the most important source of wealth in the societies we analyse. Data from land registers on types of tenure is limited and therefore must be combined with information from poll tax records concerning farm size in order to arrive at a better understanding of each household's access to land. The category peasant includes freeholders, tenants on crown land, and tenants on noble land as well as a few tenants on church land. We only include peasants with farms larger than 1/16 mantal in this category since it has been argued that peasants with smaller farms were not self-supporting. Mantal was not a measure of the actual size of the farm but a tax-assessment unit based on potential productivity. The few persons belonging to the nobility are also included in this group. The second group includes farmers with land smaller than 1/16 mantal, crofters, and the landless workers, the latter being in majority (see Bengtsson and Lindström 2000 for more details). Thus, we are only differentiating between two social groups: those with land enough to feed a family and those who need to work for someone else to be able to support a family.

The nineteenth century was a period of considerable social change in the countryside. It has been described as a period of proletarianization and pauperization (see Lundh 1983 for an overview). The numbers of landless increased (Carlsson 1968). The downward mobility was significant since many children of farmers were unable to obtain a farm themselves. This was true both for Sweden in general and for the area we study (Lundh 1998). Downward mobility was also common among the elderly, since many either sold their farms or gave them to their children. However, they could still be rather well off since the new owner of their farm often had to look after them in accordance with special contracts (undantagskontrakt). Not only did social stratification increase at the beginning of the nineteenth century, the economic condition of the landless worsened. They were, for example, more vulnerable to short-term economic stress than they were both before and after this period (Bengtsson and Dribe 2005).

The nineteenth century was also a period of rapidly expanding population in Scania as well as in Sweden in general (see Bengtsson 2001). Fertility rates were rather stable and mortality fell, first among infants and children, later among adults and the elderly. During the period we study, the crude death rate for ages 55-80 years was declining in the four parishes, as in the rest of Sweden. Life expectancy of Swedish women was the highest in the world (about 45 years around 1830) and remaining life expectancy at age 55 was about 16 years. The figures for men were several years lower. The corresponding figures for our four parishes are slightly higher than for Sweden.

Mortality in ages 55-80 years varied markedly from 1 year to the next and showed a downward trend, as was the case nationally in Sweden (Jones 1956; Fridlizius 1989). The models that we apply include a number of variables: sex, whether a person has in-migrated to the parish or not, the parish of residence, birth year, current food prices, season of birth and four other variables as indicators of conditions in early life (see Bengtsson and Lindström 2000, 2003 for details). The 
infant mortality rate in the year of birth, a time-varying community variable, is used as a fixed early-life covariate. It measures the disease load during first year of life. Here the variation from 1 year to the next is also large but diminished somewhat over time. The trend is upward for most of the eighteenth century and downward from the 1780s onwards. Thus, old-age mortality is preceded by a decline in infant mortality by about 70 years. In order to separate effects of the trend from the effects of occurring cycles in infant mortality, we have constructed two variables: a trend variable, constructed using a Hodrick-Prescott filter and a variable designed to pickup cycles, measured as deviations from the trend. We have then categorized the variable "infant mortality rate cycle" into five groups, the upper one at $0.12 .^{3}$

The aggregated indicator of the food prices is included in the regressions as a time-varying communal covariate (Bengtsson 1989, 1993). We use the deviation from the $\log$ trend in rye prices as an indicator. This means that the aggregated economic information is used as a time-varying covariate common to all individuals in the risk set at each point in calendar time. ${ }^{4}$ Both price at birth and price at the time of conception are included in the models. Thus, we estimate the effects of food availability both during pregnancy and during first year of life. We use local prices of rye, the most common crop, referring to the conditions in the fall, and we estimate the effects of food prices during the subsequent year (see Bengtsson 2001 for more details). Finally, we include mortality in ages 20-50 years as an indicator of the disease environment during pregnancy.

\subsection{Data for Sart}

Our Belgian data come from the municipality of Sart, located in the Ardennes region, close to the German border. Although the commune is geographically quite large compared to other Belgian communes, it has always been sparsely populated (42 inhabitants per square kilometer in 1846). The territory of Sart includes part of the area known as the "Hautes Fagnes," a high plateau of peat bogs and forest where agriculture has always been marginal. The population of Sart resided in a half dozen hamlets on the northern slopes of the Fagnes. Each one remains an island surrounded by forests. The area was very poor in the nineteenth century (Alter et al. 2004b).

The rural population of the Ardennes was mostly composed of smallholders on middle-sized farms. At the beginning of the nineteenth century, much of the land in Sart was held in common, and recognized members of the community had a variety of rights on common lands and forests (Vliebergh and Ulens 1912). An 1847 law encouraged the sale of common land and the formation of larger holdings, but the few large estates that resulted were abandoned shortly thereafter (Vliebergh and

\footnotetext{
${ }^{3}$ For further discussion of the functional form, see Bengtsson et al. (2002).

${ }^{4}$ We use the free software R (Hornik 2002), and the R package eha, which can handle time- varying community covariates in a simple way (Broström 2002).
} 
Ulens 1912: 62). Agricultural techniques were primitive at the beginning of the century, and farmers depended heavily on forests for both wood and feeding livestock. The population of Sart grew from about 1800 persons at the beginning of the nineteenth century to about 2500 in 1850 , and there are signs of increasing population pressure (Alter et al. 2004a). After 1850, the area was strongly affected by the rapid industrialization of the region. Sart is less than $20 \mathrm{~km}$ from Verviers and $40 \mathrm{~km}$ from Liège, two important centers of the Industrial Revolution. Out-migration to industrial centers increased rapidly after 1850 (Oris and Alter 2001). The combination of slow population decline and the introduction of new agricultural techniques raised incomes, which are reflected in rapidly rising property values.

Sart was chosen as a research site because we have exceptionally complete demographic records covering most of the nineteenth century. In 1811, the population of Sart was recorded in a register showing the names of all persons arranged in households. This register was updated to reflect changes due to births, marriages, deaths, and migration, and a new register was opened in 1843. After the national census of 1846, population registers were implemented in all of Belgium (Alter 1988). Since the population register records dates of in- and out-migration, we are able to reconstruct the population at risk at every point in time.

Previous studies have already revealed the patterns of mortality in Sart during the nineteenth century (Alter et al. 2004a; Alter and Oris 2000). The crude death rate remained approximately constant until 1870, when a sustained decline began. The influence of several major epidemics is readily apparent, including a typhus epidemic in 1816-17 following the Napoleonic Wars. Life expectancy remained stable around 42 years before 1850 and increased slowly in the second half of the century. Improvements in mortality began among children aged 1 to 10 in the period 1867-1880, and spread to adolescent and adult ages after 1880 (Alter et al. 2004a). Infant mortality, however, was largely unaffected until the last decade of the century. The infant mortality rates show no trend during the period examined. Mortality after age 55 did improve after 1850 as in Scania.

We use annual prices of oats as an indicator of economic stress in Sart ${ }^{5}$. Oats were by no means the preferred grain, because it could not be made into bread. ${ }^{6}$ As the least expensive grain, however, oats were the last resort of the poor. Previous studies have shown that an increase in the price of rye was often associated with lower mortality in Sart (Oris et al. 2005). Prices were determined on international markets, and farmers benefited from high prices as long as they had substitutes for high-priced

\footnotetext{
${ }^{5} \mathrm{We}$ have done analyses with both oats and rye, and the response was more sensitive to oats in this case. Both grains were grown in Sart, but prices were determined on international markets. In some cases we find that the grains have opposite signs when they are both included in the regression equation. The reason, we believe, is that farmers in Sart had the choice of selling their rye in urban markets when the price rose. Even if this meant that they ate more oats (the cheaper grain), it would increase their welfare. When the price of oats went up, the poor in Sart were severely affected, because (as we say in the paper) oats was their last resort.

${ }^{6}$ Prices for 1798 to 1830 were derived from Deprez (1948). Prices after 1831 come from Gadisseur (1990).
} 
grains. An increase in the price of oats had a large impact on the poor, however, because they had nowhere else to turn. Prices of oats tended to be more stable than other grains, but there were large fluctuations in prices between 1800 and 1820 . There were constant demands for men and supplies when Eastern Belgium was part of the Napoleonic Empire. A severe economic crisis accompanied by a typhus epidemic followed Napoleon's defeat.

\subsection{Results}

Table 24.2 shows the abridged results for a basic model with four early-life factors included as well as a number of control variables. The full results for Sart are shown in Appendix Table 24.5, and for Scania in Bengtsson and Lindström (2000). Our focus is whether the effect of the disease load in year at birth has a strong impact on mortality in later life both in Scania and in Sart. This, however, is not the case. Instead, we find that the impact of food prices in year of birth is important in Sart; a $10 \%$ decline in food prices reduces mortality in older ages by $14 \%$. This is the average effect for the entire population and since we can safely assume that lower strata were most negatively affected by high food prices the effect must have been even larger among the poor (Bengtsson 2004; Alter et al. 2004a).

Sources: For Scania: Bengtsson and Lindström (2003: table 2). For Sart: Appendix Table 24.6.

Table 24.3 shows the estimation results of a similar model in which the disease load in the first year of life is included as a single early-life variable but where it has been divided into a trend and a cycle component. We still find no support for the hypothesis that the disease load in first year of life has an impact on old age mortality in Sart, as it was in Scania ${ }^{7}$. This is, in fact, hardly surprising since the infant mortality rate shows almost no trend in Sart.

Turning to Table 24.4, showing possible nonlinear effects of the disease load in birth year on old age mortality, we find that children born in years of very high infant mortality in Sart also face higher mortality later in life. The result is precisely the same as for Scania, despite the fact that the study for Scania covers a much longer period, one in which infants often were exposed to a highly virulent disease smallpox. Thus, normal variation in the disease environment at birth from 1 year to the next has no impact on old-age mortality in Sart, only the extreme years have an effect in later life.

\footnotetext{
${ }^{7}$ There were no smallpox epidemics in Sart because there was a strong vaccination campaign in the early 19th century. There were isolated cases of smallpox later in the century, including a small epidemic in 1871, because physicians did not realise that the immunity conveyed by vaccination is not permanent.
} 
Table 24.2 Estimation of effects of infant mortality rate at birth, crude death rate at ages 2050 years 9 months prior to birth, and cycles in the logarithm of rye prices both 9 months prior to birth and at birth

\begin{tabular}{|c|c|c|c|c|}
\hline \multirow[b]{2}{*}{ Covariate } & \multicolumn{2}{|l|}{ Scania } & \multicolumn{2}{|l|}{ Sart } \\
\hline & Rel.risk & p-value & Rel.risk & p-value \\
\hline Infant mortality rate at birth & 2.93 & 0.00 & 1.00 & 0.33 \\
\hline Crude death rate in ages $20-50$ at conception & 0.67 & 0.91 & 0.99 & 0.62 \\
\hline Food-prices up $10 \%$ at conception & 0.65 & 0.60 & 0.86 & 0.43 \\
\hline At birth & 0.19 & 0.86 & 1.39 & 0.09 \\
\hline No. of deaths & & 1398 & & 573 \\
\hline
\end{tabular}

Sources: For Scania: Bengtsson and Lindström (2003: table 1). For Sart: Appendix Table 24.5 Note: The model controls for socioeconomic status, sex, birth year, birth season, birthplace, parish of residence, and logarithm of current rye prices in four Scanian parishes, 1766-1894, and in Sart, 1854-1899

Table 24.3 Estimation of effects of cycles and trend in infant mortality rate (IMR) at birth

\begin{tabular}{l|lllll}
\hline \multirow{2}{*}{ Covariate } & Scania & & \multicolumn{2}{l}{ Sart } & \\
\cline { 2 - 3 } \cline { 5 - 5 } & Rel.risk & p-value & & Rel.risk & p-value \\
\hline IMR at birth trend & 4.85 & 0.01 & 1.01 & 0.36 \\
Cycle & 2.35 & 0.01 & 1.00 & 0.97 \\
No. of deaths & & 1398 & & 573 \\
\hline
\end{tabular}

Note: The model controls for sex, birth year, birth season, birthplace, parish of residence, socioeconomic status, crude death rate at ages 20-50 years 9 months prior to birth, and cycles in the logarithm of rye prices 9 months prior to birth, at birth, and currently in four Scanian parishes, 1766-1894, and in Sart, 1854-1899

Table 24.4 Estimation of nonlinear effects of cycles in infant mortality rate at birth

\begin{tabular}{|c|c|c|c|c|}
\hline \multirow[b]{2}{*}{ Covariate } & \multicolumn{2}{|l|}{ Scania } & \multicolumn{2}{|l|}{ Sart } \\
\hline & Rel.risk & p-value & Rel.risk & p-value \\
\hline IMR at birth & & & & \\
\hline Very low & 1.03 & 0.90 & - & - \\
\hline Low & 1.01 & 0.93 & 1.14 & 0.26 \\
\hline Normal & 1.00 & - & 1.00 & - \\
\hline High & 0.91 & 0.28 & 0.89 & 0.28 \\
\hline Very high & 1.51 & 0.02 & 1.58 & 0.02 \\
\hline No. of deaths & & 1398 & & 573 \\
\hline
\end{tabular}

Note: The model controls for sex, birth year, birth season, birthplace, parish of residence, socioeconomic status, crude death rate at ages 20-50 years 9 months prior to birth, and cycles in the logarithm of rye prices 9 months prior to birth, at birth and currently in four Scanian parishes, 17661894, and in Sart, 1854-1899

Sources: For Scania: Bengtsson and Lindström (2003: table 3). For Sart: Appendix Table 24.7 


\subsection{Discussion}

In a large body of studies, the conclusion is that conditions very early in life, in the fetal stage and in the first year of life, have an impact on health and mortality in later life. Robert Fogel (1994) has proposed several plausible causal mechanisms that connect malnutrition in utero and during early life to chronic diseases in later life. Fogel's propositions have been supported by the work of Barker $(1994,1995)$ who has suggested that the preconditions for coronary heart disease, hypertension, stroke, diabetes, and chronic thyroiditis are initiated in utero but do not become clinically manifest until much later in life. To the extent that the damage caused by malnutrition in early life shows up later in life, we label it "permanent" damage. Recent reviews of the evidence are given by Finch and Crimmins (2004) and Lindström and Davey Smith in this volume.

For Scania, we have previously shown that the disease load in the birth year affected mortality in ages 55-80 years, while we have found no support for either the in utero or the diseases environment during pregnancy hypotheses (Bengtsson and Lindström 2000, 2003; Bengtsson et al. 2002). The question we raise in this paper is whether this is a "Swedish" phenomenon or if it can be found elsewhere. On the one hand, we find support for the hypothesis of disease load in year at birth also for nineteenth century Sart, a rural parish in eastern Belgium. On the other hand, not only the disease load but also the food availability in year at birth affected old age mortality in Sart. Neither in Sart nor in Scania have we found any in utero effects.

As regards the impact of the disease load during infancy, in Sart we find a threshold effect but no basic effect (linear) and no trend effect. When we analyze the period 1829-1894 in Scania, we find threshold effects almost identical to those in Sart (Bengtsson and Broström 2003). Over the longer period from 1766 to 1894 the results for Scania are driven both by the trend in infant mortality, which also appears in analyses of aggregated data (Jones 1956; Fridlizius 1989; Finch and Crimmins 2004), and by extreme values. In the eighteenth century, most years with very high infant mortality were years with high smallpox mortality (Bengtsson and Lindström 2003: Table 24.4) but smallpox was much less important in nineteenth-century Sart - and the sub-period 1829-1894 for Scania. Thus, other epidemic diseases like whooping cough, for Scania, and typhus and cholera, for Sart, had effects in old age mortality similar to those of smallpox.

Another interesting finding is that food prices in the year of birth also affected later life mortality in Sart. Could it be that when highly virulent diseases (smallpox) disappear, socioeconomic conditions gain in importance, at least relatively speaking but perhaps also in absolute terms? If this is the case, then it fits well with the observation that socioeconomic factors were gradually becoming more and more important for mortality levels during the course of the nineteenth century.

Finally, we turn to a brief discussion of the use of early-life indicators to improve mortality forecasting. Several studies have shown that the disease load early in life can cause permanent damage that shows up in increased mortality risks later in life. This was the case for Sweden, using aggregate level data, as well as for a rural 
population in the very south of Sweden, using micro level data. This was also the case for Sart in eastern Belgium, also using individual level data, as shown in this study. Several other recent studies show similar results for other parts of Europe, as well as for Canada (for an overview, see Beise et al. 2006; Schuster and Sunder 2005). Taken together, these findings suggest that the disease load early in life can be used to predict mortality later in life. Finch and Crimmins (2004), however, find that whereas mortality in the first year of life is of most importance for mortality risks at older ages in some countries, mortality in childhood is more important in other countries. This constitutes a problem since it implies different mechanisms. If the mechanism in play had been the same and remained stable across populations, its value as a predictor of future mortality would certainly be much higher.

Acknowledgement This work has been done within three projects: Early-Life Conditions, Social Mobility, and Longevity: Social Differences and Trends in Adult Mortality in Sweden, 1650-1900, financed by the Swedish Council for Working Life and Social Research; Early-Life Conditions, Social Mobility, and Health in Later Life, financed by the Bank of Sweden Tercentenary Foundation, and Early-Life Conditions, Social Mobility, and Longevity, P01 AG18314, financed by the National Institute of Aging, USA. The Swedish data come from the Scania Demographic Database, which is a collaborative project between the Regional Archives in Lund and the Department of Economic History at Lund University.

\section{Appendix}

Table 24.5 Sart, 1855-1899. Estimation of effects of infant mortality rate at birth, crude death rate at ages 20-50 years 9 months prior to birth, and cycles in the logarithm of out prices both 9 months prior to birth and at birth, controlling for socioeconomic status, sex, birth year, birth season, birth place. The number of deaths is 573

\begin{tabular}{lllll}
\hline Subjects & & 658 & & \\
Deaths & & 573 & & \\
Time at risk & & 8770.889 & & \\
Log likelihood & & -3070.84 & & \\
$\mathrm{p}$ & & 0 & & \\
& & Rel.risk & p-value & Mean \\
Female & & 0.91 & 0.28 & 0.47 \\
Year of birth & & 1.04 & 0.00 & 1821.42 \\
Birth season: & Jan-Mar & & & \\
& Apr-Jun & 1.00 & & 27.21 \\
& Jul-Sep & 1.09 & 0.49 & 25.11 \\
& Oct-Dec & 0.94 & 0.61 & 21.64 \\
& & 1.20 & 0.10 & 26.03 \\
Wealth after age 55 & None & & & \\
& Low & 1.00 & & 36.63 \\
& High & 1.19 & 0.07 & 43.47 \\
& & 0.70 & 0.00 & 19.91 \\
\hline
\end{tabular}


Table 24.5 (continued)

\begin{tabular}{|c|c|c|c|}
\hline Born in Sart & 1.13 & 0.24 & 0.70 \\
\hline IMR year of birth & 1.00 & 0.33 & 169.86 \\
\hline Adult Death Rate year before birth (difference from trend) & 0.99 & 0.62 & 0.12 \\
\hline $\begin{array}{l}\text { Oats year of birth } \\
\text { (difference from trend in logs) }\end{array}$ & 1.39 & 0.09 & 0.00 \\
\hline Oats year before birth (difference from trend in logs) & 0.86 & 0.43 & 0.00 \\
\hline
\end{tabular}

Table 24.6 Sart, 1855-1899. Estimation of effects of cycles and trend in infant mortality rate at birth controlling for socioeconomic status, sex, birth year, birth season, birth place. The number of deaths is 573

\begin{tabular}{lllll}
\hline Subjects & & 658 & \\
Deaths & & 573 & \\
Time at risk & 8770.889 & & \\
Log likelihood & & -3071.97 & & \\
P & & & \\
& & Rel.risk & p-value & Mean \\
Female & & 0.90 & 0.24 & 0.47 \\
Year of birth Birth season: & Jan-Mar & 1.04 & 0.00 & 1821.42 \\
& & 1.00 & & 27.21 \\
& Apr-Jun & 1.07 & 0.58 & 25.11 \\
& Jul-Sep & 0.93 & 0.58 & 21.64 \\
Wealth after age 55 & Oct-Dec & 1.21 & 0.09 & 26.03 \\
& None & 1.00 & & 36.63 \\
& Low & 1.22 & 0.04 & 43.47 \\
Born in Sart & High & 0.70 & 0.00 & 19.91 \\
IMR Trend year of birth & & 1.14 & 0.23 & 0.70 \\
IMR Cycle year of birth & & 1.01 & 0.36 & 161.80 \\
\hline
\end{tabular}

Table 24.7 Sart, 1855-1899. Estimation of threshold effects of infant mortality rate at birth controlling for socioeconomic status, sex, birth year, birth season, birth place. The number of deaths is 573

\begin{tabular}{|c|c|c|c|}
\hline Subjects & \multicolumn{3}{|l|}{658} \\
\hline Deaths & \multicolumn{3}{|l|}{573} \\
\hline \multirow[t]{2}{*}{ Time at risk Log likelihood $\mathrm{P}$} & & -3068.41 & \\
\hline & Rel.risk & p-value & Mean \\
\hline Female & 0.90 & 0.21 & 0.47 \\
\hline Year of birth Birth season: & 1.04 & 0.00 & 1821.42 \\
\hline Jan-Mar & 1.00 & & 27.21 \\
\hline
\end{tabular}


Table 24.7 (continued)

\begin{tabular}{lllll}
\hline & Apr-Jun & 1.07 & 0.56 & 25.11 \\
Wealth after age 55 & Jul-Sep & 0.94 & 0.60 & 21.64 \\
& Oct-Dec & 1.21 & 0.09 & 26.03 \\
& None & 1.00 & & 36.63 \\
& Low & 1.22 & 0.04 & 43.47 \\
Born in Sart & High & 0.72 & 0.01 & 19.91 \\
IMR in year of birth & & 1.14 & 0.23 & 0.70 \\
& Low & 1.14 & 0.26 & 21.92 \\
& Normal & 1.00 & & 47.49 \\
& High & 0.89 & 0.28 & 21.19 \\
& Very high & 1.58 & 0.02 & 9.41 \\
\hline
\end{tabular}

\section{References}

Alter, G. (1988). Family and the female life course: The women of Verviers, Belgium, 1849-1880. Madison: University of Wisconsin Press.

Alter, G., Neven, M., \& Oris, M. (2004a). Mortality and modernization in Sart and surroundings, 1812-1900. In T. Bengtsson, C. Campbell, J. Z. Lee, et al. (Eds.), Life under pressure: Mortality and living standards in Europe and Asia, 1700-1900 (pp. 173-208). Cambridge, MA: MIT Press.

Alter, G., Neven, M., \& Oris, M. (2004b). Stature in transition: A micro-level study from nineteenth-century Belgium. Social Science History, 28(2), 231-247.

Alter, G., \& Oris, M. (2000). Mortality and economic stress: Individual and household responses in a nineteenth-century Belgian village. In T. Bengtsson \& O. Saito (Eds.), Population and economy. From hunger to modern economic growth (pp. 335-370). Oxford: Oxford University Press.

Barker, D. J. P. (1994). Mothers, babies, and disease in later life. London: British Medical Journal Publishing Group.

Barker, D. J. P. (1995). Fetal origins of coronary heart disease. British Medical Journal, 311, 171-175.

Beise, J., Desjardin, B. \& Johansson, K. (2006). Early life conditions and adult mortality in the St. Lawrence Valley, Canada, 1700-1850. Paper presented at the Annual Meeting of the Population Association of America, Los Angeles, March 30-April 1, 2006.

Bengtsson, T. (1989). Real wage variations and adult mortality: Life events in Västanfors, 1750-1859. Paper presented at the IUSSP General Conference, New Delhi.

Bengtsson, T. (1993). Combined time-series and life event analysis: The impact of economic fluctuations and air temperature on adult mortality by sex and occupation in a Swedish mining parish. In D. Reher \& R. Schofield (Eds.), Old and new methods in historical demography (pp. 239-258). Oxford/New York: Clarendon Press/Oxford University Press.

Bengtsson, T. (2001). Mortality: The great historical decline. International Encyclopedia of the Social and Behavioral Sciences, Elsevier Science Ltd, pp. 10079-10084. Available online at: http://www.sciencedirect.com/science/referenceworks/0080430767

Bengtsson, T. (2004). Mortality and social class in four Scanian parishes, 1766-1865. In T. Bengtsson, C. Campbell, J. Z. Lee, et al. (Eds.), Life under pressure. Mortality and living standards in Europe and Asia, 1700-1900 (pp. 135-171). Cambridge, MA: MIT Press. 
Bengtsson, T., \& Broström, G. (2003). How conditions in early-life and social mobility influence mortality in later life: Southern Sweden, 1829-1894. Paper presented at the SSHA conference, November 13-16, 2003, Baltimore, USA.

Bengtsson, T., \& Broström, G., \& Lindström, M. (2002). Effects of conditions in early-life on old age mortality in southern Sweden, 1766-1894: Functional form and frailty. Paper presented at the ESSHC, February 27-March 2, 2002, Den Haag, The Netherlands.

Bengtsson, T., \& Dribe, M. (2005). New evidence on the standard of living in Sweden during the eighteenth and nineteenth centuries: Long-term development of the demographic response to short-term economic stress. In R. C. Allen, T. Bengtsson, \& M. Dribe (Eds.), Living standards in the past. New perspectives on well-being in Asia and Europe (pp. 341-372). Oxford: Oxford University Press.

Bengtsson, T., \& Lindström, M. (2000). Childhood misery and disease in later life: The effects on mortality in old age of hazards experienced in early life, southern Sweden, 1760-1894. Population Studies, 54, 263-277.

Bengtsson, T., \& Lindström, M. (2003). Airborne infectious diseases during infancy and mortality in later life, southern Sweden, 1766-1894. International Journal of Epidemiology, 32, 286-294.

Broström, G. (2002). MLife. http://tal.stat.umu.se/ gb/Mlife/. Umeå: Umeå University.

Carlsson, S. (1968). Yrken och samhällsgrupper: den sociala omgrupperingen i Sverige efter 1860. Stockholm: Almqvist \& Wiksell.

Cox, D. R. (1972). Regression models and life-tables (with discussion). Journal of the Royal Statistical Society, Series B, 34, 187-220.

Deprez M. (1948). Essai sur le mouvement des prix et des revenus en Belgique au début du 19e siècle (1798-1830). Unpublished thesis, University of Liège.

Elo, I. T., \& Preston, S. H. (1992). Effects of early-life conditions on adult mortality: A review. Population Index, 58(2), 86-212.

Finch, C. E., \& Crimmins, E. M. (2004). Inflammatory exposure and historical changes in human life-spans. Science, 305, 1736-1739.

Fogel, R. W. (1994). The relevance of Malthus for the study of mortality today: Long-run influences on health, mortality, labour-force participation and population growth. In K. Lindvall \& H. Landberg (Eds.), Population, economic development, and the environment: The making of our common future (pp. 231-284). Oxford/New York: Oxford University Press.

Fridlizius, G. (1989). The deformation of cohorts: Nineteenth-century mortality in a generational perspective. Scandinavian Economic History Review, 37, 3-17.

Gadisseur, J. (1990). Le produit physique de la Belgique, 1830-1913. Brussels: Palais des Académies.

Hornik, K. (2002). The R FAQ. Available online at http://www.ci.tuwien.ac.at/ hornik/R/. ISBN 3-901167-51-X.

Jones, H. B. (1956). A special consideration of the aging process, disease, and life expectancy. In J. H. Lawrence \& C. A. Tobias (Eds.), Advances in biological and medical physics (Vol. 4, pp. 281-337). New York: Academic.

Kermack, W. O., McKendrick, A. G., \& McKinlay, P. L. (1934). Death rates in Great Britain and Sweden: Some regularities and their significance. Lancet, 1, 698-703.

Kuh, D., \& Ben-Shlomo, Y. (1997). A life course approach to chronic disease epidemiology. Oxford: Oxford University Press.

Lindström, M., \& Davey Smith, G. (2008). A Life Course Perspective to the Modern Secular Mortality Deline and Socioeconomic Differences in Morbidity and Mortality in Sweden. In T. Bengtsson (Ed.), Perspectives on Mortality Forecasting, Social Insurance Studies, No. 5: Cohort factors: How conditions in early life influence mortality later in life. Stockholm: Swedish Social Insurance Agency.

Lundh, C. (1983). "Levnadsstandarden - indikatorer och mått. Engelsk och svensk debatt om lönearbetarnas villkor 1750-1850." Meddelande från Ekonomisk-historiska institutionen, no. 23. Lund: Dept. of Economic History, Lund University. 
Lundh, C. (1998). Servant migration in the early nineteenth century. Journal of Family History, 24, $53-73$.

Oris, M., \& Alter, G. (2001). Paths to the city and roads to death: Mortality and migration in East Belgium during the industrial revolution. In I. Devos \& M. Neven (Eds.), Recent Work in Belgium Historical Demography 19th and Early 20th centuries. Special issue. Revue Belge d'Histoire Contemporaine, 31(3-4), 453-495.

Oris, M., Neven, M., \& Alter, G. (2005). Individuals and communities facing economic stress: A comparison of two rural areas in 19th century Belgium. In R. C. Allen, T. Bengtsson, \& M. Dribe (Eds.), Living standards in the past. New perspectives on well-being in Asia and Europe (pp. 373-402). Oxford: Oxford University Press.

Preston, S. H., Hill, M. E., \& Drevenstedt, G. L. (1998). Childhood conditions that predict survival to advanced ages among African-Americans. Social Science and Medicine, 47, 1231-1246.

Riley, J. C. (2001). Rising life expectancy: A global history. Cambridge: Cambridge University Press.

Rotberg, R. I., \& Rabb, T. K. (1985). Hunger and history: The impact of changing food patterns and society. Cambridge/London: Cambridge University Press.

Schuster K., \& Sunder, M. (2005). Stature and twist of fate: Evidence on the biological standard of living from the lives and deaths of 19th-century Bavarian men. Manuscript, Dec. 16, 2006.

Sköld, P. (1996). The two faces of smallpox: A disease and its prevention in eighteenth- and nineteenth-century Sweden. Umeå: The Demographic Data Base, Umeå University.

Therneau, T. M., \& Grambsch, P. M. (2000). Modeling survival data: Extending the Cox model. New York: Springer.

Vliebergh, E., \& Ulens, R. (1912). L’Ardenne. La Population Agricole Au XIXe Siècle. Brussels: Librairie Albert Dewit.

Open Access This chapter is licensed under the terms of the Creative Commons Attribution 4.0 International License (http://creativecommons.org/licenses/by/4.0/), which permits use, sharing, adaptation, distribution and reproduction in any medium or format, as long as you give appropriate credit to the original author(s) and the source, provide a link to the Creative Commons license and indicate if changes were made.

The images or other third party material in this chapter are included in the chapter's Creative Commons license, unless indicated otherwise in a credit line to the material. If material is not included in the chapter's Creative Commons license and your intended use is not permitted by statutory regulation or exceeds the permitted use, you will need to obtain permission directly from the copyright holder. 